\title{
Interaction of Different Metal Ions with Carboxylic Acid Group: A Quantitative Study
}

\author{
Tanushree Bala, $^{1}$ B. L. V. Prasad ${ }^{1}$ and Murali Sastry ${ }^{{ }^{1 \dagger}}$ \\ and \\ Mousumi Upadhyay Kahaly ${ }^{2}$ and Umesh V. Waghmare ${ }^{2^{*}}$ \\ ${ }^{1}$ Materials Chemistry Division, National Chemical Laboratory, Pune - 411008 , INDIA \\ ${ }^{2}$ Theoretical Sciences Unit, Jawaharlal Nehru Centre for Advanced Scientific Research, Jakkur \\ PO, Bangalore 560 064, INDIA
}

\section{Supporting Information 1}

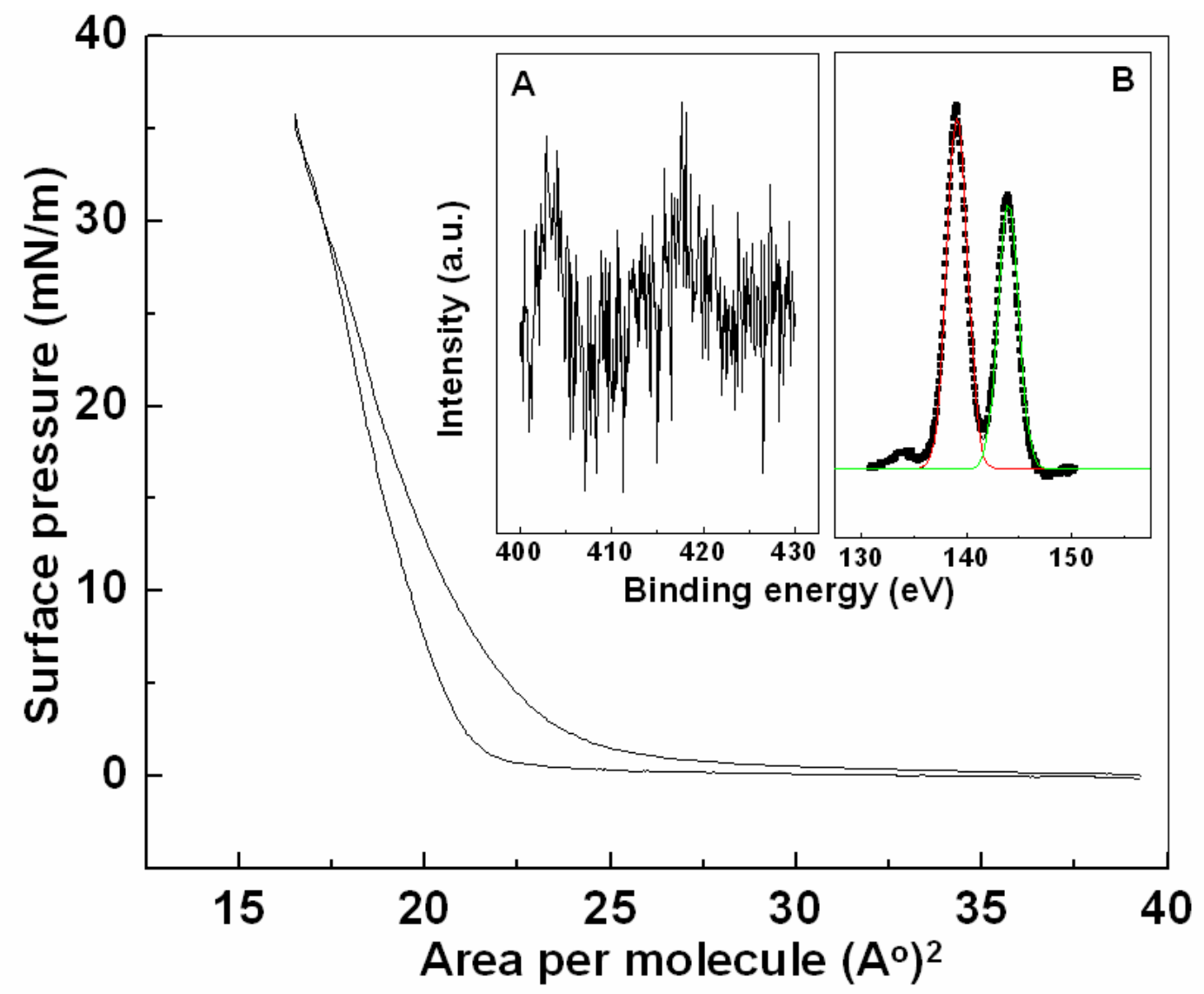

S-1: The figure demonstrates the pressure-area isotherm of pure AA spread over the subphase of equimolar mixture of $\mathrm{Cd}^{2+}$ and $\mathrm{Pb}^{2+}$. The XPS spectra of the ions performed on a film lifted from the LB trough at a pressure $30 \mathrm{mN} / \mathrm{m}$ are presented as inset $\mathrm{A}\left(\right.$ for $\mathrm{Cd}^{2+}$ ) and $\mathrm{B}\left(\right.$ for $\mathrm{Pb}^{2+}$ ). 